\title{
PERENCANAAN GARDU DISTRIBUSI FAKULTAS KEGURUAN DAN ILMU PENDIDIKAN UNIVERSITAS TADULAKO
}

\author{
Arifudin $^{1}$, Tribianto ${ }^{2}$, Muhammad Sarjan ${ }^{3}$, Baso Mukhlis ${ }^{4}$ \\ ${ }^{2}$ Fakultas Teknik, Jurusan Teknik Elektro, Universitas Tadulako \\ Email: tribianto6@gmail.com \\ ${ }^{1}$ Fakultas Teknik, Jurusan Teknik Elektro, Universitas Tadulako \\ Email: ariarifudin94@gmail.com
}

\begin{abstract}
The Faculty of Teacher Training and Education is one of the Faculties that has the most buildings in Tadulako University, which of course requires large capacity electrical equipment facilities and also requires large electric power as well. To provide optimal services so that lecture, practicum and other activities are not disrupted due to electrical problems. Electricity problems at the Faculty of Teacher Training and Education are currently caused by excessive loading that is not adjusted to the transformer capacity at the Economic Substation, The distance that is served by the Economic Substation is approximately 950 meters so that it causes losses on the network.

Based on the calculation of the total load obtained for lighting, room conditioning and auxiliary contact boxes of $167,402 \mathrm{kVA}$ and considering the addition of Loads and Buildings within the Faculty of Teacher Training and Education, the transformer capacity used is $\mathbf{2 0 0}$ kVA and according to SPLN Transformers with capacities below 200 kVA must use Portal substation construction.
\end{abstract}

Keywords " Portal Substation, FKIP Substation Planning.”

\section{PENDAHULUAN}

Fakultas Keguruan dan Ilmu Pendidikan merupakan salah satu Fakultas yang memiliki, tentunya membutuhkan fasilitas peralatan listrik yang berkapasitas besar dan membutuhkan tenaga listrik yang besar pula. Untuk menyediakan pelayanan yang optimal sehingga kegiatan perkuliahan, praktikum dan kegiatan lainnya tidak terganggu karena masalah kelistrikan. Adapun permalasahan yang terjadi saat ini adalah jatuh nya tegangan pada fakultas keguruan dan ilmu pendidikan.

Permasalahan ini disebabkan Panjangnya jarak jaringan dari gardu ekonomi untuk menyuplai fakultas keguruan dan ilmu pendidikan yang tidak mengikuti prasyaratan, standar serta peraturan ketenagalistrikan. Standar peraturan yang dimaksudkan yaitu SPLN sesuai keputusan direksi PT.PLN Persero No: 475, 605, 474, 473, 606. K/DIR/2010 dan peraturan lain yang menunjang. [3] Tujuan dari pemberlakuan peraturan tersebut adalah untuk menjamin keselamatan manusia, ternak dan harta benda, serta syarat utama penyediaan tenaga listrik dapat dilaksanakan secara aman, andal dan akrab lingkungan. Penelitian yang pernah dilakukan sebelumnya yang berhubungan dengan perencaan gardu distribusi fakultas keguruan dan ilmu pendidikan antara lain adalah:

1. Penelitian Ridawati. (2013), yang berjudul "Perencanaan gardu distribusi khusus indoor tegangan menengah $20 \mathrm{kV}$ Iain Imam Bonjol Padang". [6]

2. Penelitian Lisma(2013), penelitian yang berjudul "Perencanaan pemasangan gardu sisip P117 di PT.PLN Persero Area Bangka".

3. penelitian, Sutanto Hamad dan Riswanda (2017), yang berjudul "Pemasangan gardu beton Auditorium Universitas Tadulako". [4]

Dari tiga penelitian tersebut memiliki kesamaan dengan penelitian ini, yaitu sama sama merencanakan gardu distribusi.

\section{METODE PENELITIAN}

Penelitian berada di Fakultas Keguruan Dan Ilmu Pendidikan Universitas Tadulako dan Waktu yang dibutuhkan selama penelitian ini selama \pm 2 bulan dari Bulan Maret - Mei 2018.

Metodelogi yang digunakan dalam penelitian yang berjudul Perencanaan Gardu 
Portal Fakultas Keguruan Dan Ilmu Pendidikan Universitas Tadulako sebagai berikut:

\section{Observasi}

Untuk mendapatkan data penelitian, penulis melakukan Observasi, dengan survey lokasi penelitian yaitu Gedung Dekanat, Jurusan Pendidikan Jasmani Kesehatan dan Rekreasi, Gedung Serba Guna, Sekretariat Bersama dan Mushola di Fakultas Keguruan dan Ilmu Pendidikan Universitas Tadulako

2. Pengambilan Data

Pengambilan data yang akan diambil yakni keadaan lokasi penelitian peta/denah dan jumlah penggunaan listrik pada Gedung Dekanat, Jurusan Pendidikan Jasmani Kesehatan dan Rekreasi, Gedung Serba Guna, Sekretariat Bersama dan Mushola di Fakultas Keguruan dan Ilmu Pendidikan Universitas Tadulako.

\section{Studi literatur}

Studi Literatur, yaitu dengan membaca teoriteori yang berkaitan dengan topik Skripsi yang terdiri dari buku-buku referensi yang sesuai dengan tugas akhir

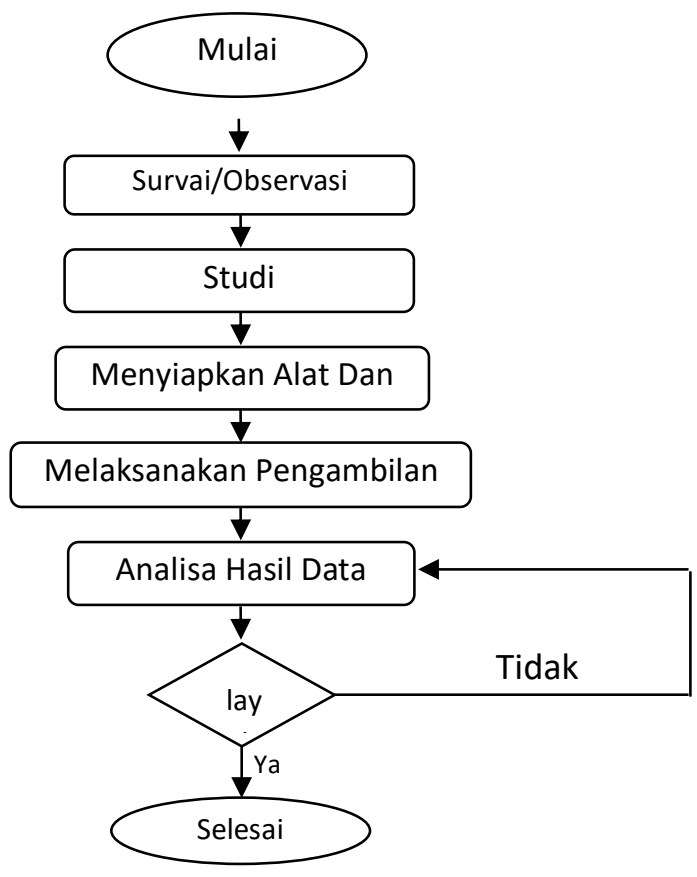

Gambar 1. Diagram Alur Metode Penelitian

Agar penelitian ini dapat berjalan dengan baik, maka penyusunan tugas akhir dilaksanakan secara sistematik melalui tahapan-tahapan sebagaimana digambarkan pada diagram alir tersebut di atas. :

a. Studi Literatur/Studi Pustaka

Proses memulai membaca buku-buku dan browsing buku referensi, standar dan jurnal tentang sistem distribusi serta peralatan listrik tegangan Rendah sehingga mempermudah dalam proses penulisan penelitian selanjutnya.

b. Pemilihan Lokasi Penelitian

Pada langkah ini penentuan lokasi penelitian pada Gedung Dekanat, Jurusan Pendidikan Jasmani Kesehatan dan Rekreasi, Gedung Serba Guna, Sekretariat Bersama dan Mushola di Fakultas Keguruan dan Ilmu Pendidikan Universitas Tadulako

c. Menyiapkan Alat dan Bahan Penelitian Proses ini dilakukan untuk menyiapkan alat dan bahan penelitian sebelumdilakukannya penelitian.

d. Melaksanakan Pengambilan Data

Proses ini merupakan pengambilan data berupa Keadaan peta/denah lokasi penelitian dan jumlah kebutuhan listrik pada Gedung Dekanat, Jurusan Pendidikan Jasmani Kesehatan dan Rekreasi, Gedung Serba Guna, Sekretariat Bersama dan Mushola di Fakultas Keguruan dan Ilmu Pendidikan Universitas Tadulako

e. Analisa Data

Berupa proses menganalisa data hasil pengambilan data yang kemudian akan dilaksanakan proses perhitungan jumlah kapasitas transformator yang di gunakan, pemilihan jenis kabel, pemilihan pengamanan listrik dan bangunan gardu yang akan dibuat.

f. Layak Indikator kelayakan adalah apabila hasil dari analisa data mengalami permasalahan maka proses analisa akan dilaksanakan kembali.

g. Kesimpulan

Setelah semua proses telah selesai dilaksanakan barulah melangkah ke proses kesimpulan sehingga akan mempermudah untuk proses selanjutnya.

\section{HASIL DAN PEMBAHASAN}

Fakultas Keguruan dan Ilmu Pendidikan merupakan salah satu Fakultas yang memiliki 
bangunan terbanyak di Universitas Tadulako, tentunya membutuhkan fasilitas peralatan listrik yang berkapasitas besardan membutuhkan tenaga listrik yang besar pula. Untuk menyediakan pelayanan yang optimal sehingga kegiatan perkuliahan, praktikum dan kegiatan lainnya tidak terganggu karena masalah kelistrikan. Untuk itu sesuai kebutuhannya baik untuk penerangan, suhu ruangan, maupun kotak kontak (KKB) harus didata sedetail mungkin untuk menentukan besar kapasitas Transformator yang akan digunakan.

\subsection{Data Beban Listrik}

Beban listrik pada Gedung Dekanat, Jurusan Pendidikan Kesehatan Jasmani dan Rekreasi, Musholah, Gedung Serba Guna, PPLM dan Sekretariat Bersama terdiri dari beban untuk penerangan (pencahayaan), beban untuk pengkondisian ruangan (AC), dan kotak Kontak (KKB). Jumlah data beban dapat di lihat pada tabel 1.

Tabel 1. Data Beban Listrik

\begin{tabular}{|c|c|c|}
\hline NO & GEDUNG & DAYA (VA) \\
\hline 1 & DEKANAT FKIP & $91378 \mathrm{VA}$ \\
\hline 2 & JURUSAN PJKR & $44878 \mathrm{VA}$ \\
\hline 3 & MUSHOLAH & $10536 \mathrm{VA}$ \\
\hline 4 & $\begin{array}{c}\text { GEDUNG SERBA } \\
\text { GUNA }\end{array}$ & 8750 VA \\
\hline 5 & PPLM & $4700 \mathrm{VA}$ \\
\hline 6 & $\begin{array}{l}\text { SEKRETARIAT } \\
\text { BERSAMA }\end{array}$ & $7160 \mathrm{VA}$ \\
\hline \multicolumn{2}{|c|}{$\begin{array}{l}\text { TOTAL BEBAN DAYA } \\
\text { LISTRIK }\end{array}$} & $\begin{array}{l}167402 \text { VA }= \\
167,402 \text { Kva }\end{array}$ \\
\hline
\end{tabular}

\subsection{Penentuan Kapasitas transformator}

Berdasarkan perhitungan kebutuhan daya listrik di wilayah Fakultas Keguruan Dan Ilmu Pendindikan Khususnya pada Gedung Dekanat, Jurusan Pendidikan Kesehatan Jasmani dan Rekreasi, Musholah, Gedung Serba Guna, PPLM dan Sekretariat Bersama sebesar 154,45 kVA. Dikarenakan Perencanaan Jaringan distribusi ini untuk perioda jangka panjang maka kapasitas Transformator yang digunakan sebesar 200 kVA sudah cukup mampu untuk melayani kebutuhan beban listrik pada bangunan tersebut. [2]

Spesifikasi Transformator Distribusi harus sesuai dengan Standar PLN (SPLN) 50:1997, yang meliputi ketentuan-ketentuan yang lebih spesifik sesuai dengan kebutuhan. [1]

\subsection{Perencanaan gardu portal}

Gardu portal adalah gardu listrik dengan konstruksi pada dua tiang atau lebih. Transformator dipasang pada bagian atas dan lemari panel/PHB-TR pada bagian bawah. Perencanaan gardu Portal ini mengacu pada lampiran Keputusan Direksi PT PLN (Persero), Nomor: 605.K/DIR/2010 Buku 4 tentang Standar Konstruksi Gardu Distribusi dan Gardu Hubung Tenaga Listrik.

\subsection{Perencanaan Perlengkapan Hubung Bagi}

a. PHB Tegangan Rendah

Perlengkapan Hubung Bagi Tegangan Rendah adalah suatu kombinasi dari satu atau lebih peralatan switching tegangan rendah dengan peralatan kontrol, ukur, pengaman dan pengaturan yang saling berhubungan.

Keseluruhan komponen ini dirakit lengkap dengan sistem pengawatan

\subsection{Perencanaan Peralatan Pengaman}

a. Pengaman Tegangan Lebih (Arrester)

Tegangan lebih biasa pula disebut tegangan surya yang terjadi pada suatu sistem tenaga listrik, disebabkan oleh sejumlah faktor. Besar tegangan ini dapat mencapai nilai yang sangat besar (umumnya dalam satuan $\mathrm{kV}$ ), sehingga akan menghasilkan arus dalam ribuan kiloAmpere.

Hal ini akan membawa akibat buruk tidak saja pada jaringan transmisi dan distribusi tenaga listrik tetapi juga pada peralatan-peralatan listrik yang tersambung dan disuplai oleh jaringan tersebut.

b. Pengaman Arus Lebih Sisi Tegangan Menengah

Salah satu jenis gangguan yang umum terjadi pada saluran distribusi adalah terjadinya hubung singkat antara fasa maupun antara fasa dengan tanah. Gangguan hubung singkat akan menyebabkan pengaliran arus gangguan yang besar yang dapat menyebabkan tidak hanya 
kerusakan pada transformator distribusi maupun peralatan listrik yang terpasang, tetapi juga akan membahayakan jiwa serta kerugian harta benda karena kebakaran.

\section{c. Pengaman Arus Lebih Sisi Tegangan Rendah}

Pengaman hubung singkat untuk jaringan distribusi sekunder (tegangan rendah) digunakan pelebur dengan kapasitas pemutusan tinggi (HRC fuse), umumnya menggunakan NT/NH fuse sebagai pengaman kabel jurusan.

Pada fuse jenis ini, elemen fuse (fuse link) dikelilingi oleh suatu gas innert sebagai medium pemadam busur api dan tertutup rapat dalam wadah keramik dengan ketahanan mekanis yang bagus. Fuse link ini dapat diganti jika sudah putus.

Dalam bentuk sederhana, sebuah fuse HRC terdiri dari rangka keramik berbentuk bundar yang biasanya dari material stealite, elemen perak murni atau elemen bimetal, serbuk quartz (kuarsa) murni, ujung penutup metal(brass end cup) dan pisau kontak dari tembaga.

Elemen fuse (fuse link) diletakkan di dalam rangka keramik dan ruang antara elemen fuse ini dengan permukaan bagian dalam tabung keramik di isi dengan serbuk quartz murni. Ujung dari fuse link disambung dengan tutup metal yang dibaut ke tabung keramik.

\begin{tabular}{|c|c|c|c|c|c|c|c|}
\hline \multirow{4}{*}{$\begin{array}{l}\text { Jenis } \\
\text { Kabel }\end{array}$} & \multirow{4}{*}{$\begin{array}{c}\text { Luas } \\
\text { Penampang } \\
\mathrm{mm}^{2}\end{array}$} & \multicolumn{6}{|c|}{ KHA terds menerols } \\
\hline & & \multicolumn{2}{|c|}{$\begin{array}{l}\text { Berinti } \\
\text { tungagl }\end{array}$} & \multicolumn{2}{|c|}{ Berintin 2} & \multicolumn{2}{|c|}{ Berinti 3 \& 4} \\
\hline & & $\mathrm{di}$ & $\mathrm{Di}$ & $\mathrm{di}$ & $\mathrm{Di}$ & $\mathrm{di}$ & $\overline{\mathrm{Di}}$ \\
\hline & & Tanal & udara & Tanah & udaras & Tanah & udaras \\
\hline 1 & 2 & 3 & 4 & 5 & 6 & 7 & 8 \\
\hline \multirow{16}{*}{$\begin{array}{c}\text { NYY } \\
\text { NYBY } \\
\text { NZZEGbY } \\
\text { NYKRGGW }\end{array}$} & 6 & 90 & 58 & 68 & 48 & 56 & 43 \\
\hline & 10 & 122 & 79 & 92 & 69 & 75 & 60 \\
\hline & 16 & 160 & 105 & 121 & 89 & 98 & 80 \\
\hline & 25 & 206 & 140 & 153 & 118 & 128 & 106 \\
\hline & 35 & 249 & 174 & 182 & 145 & 157 & 131 \\
\hline & 50 & 296 & 212 & 222 & 176 & 185 & 159 \\
\hline & 70 & 365 & 269 & 272 & 224 & 228 & 202 \\
\hline & 95 & 438 & 331 & 328 & 271 & 275 & 244 \\
\hline & 120 & 499 & 386 & 375 & 314 & 313 & 282 \\
\hline & 150 & 561 & 442 & 419 & 361 & 353 & 324 \\
\hline & 185 & 637 & 511 & 475 & 412 & 399 & 371 \\
\hline & 240 & 743 & 612 & 550 & 484 & 464 & 436 \\
\hline & & & & & & & \\
\hline & 300 & 843 & 707 & 575 & 590 & 524 & 481 \\
\hline & 400 & 986 & 859 & 605 & 710 & 600 & 560 \\
\hline & 500 & 1125 & 1000 & - & - & - & - \\
\hline
\end{tabular}

Sedangkan ujung dari pisau kontak dilas dengan penutup metal tersebut. Pisau kontak dibaut atau disipkan pada kontak stasioner yang terpasang pada panel listrik.

\subsection{Perhitungan KHA dan Diameter Kabel}

Pemilihan diameter kabel yang menyuplai listrik dari gardu portal ke Panelbangunan,berdasarkan SNI-04-02252000 tentang Persyaratan Umum Instalsi Listrik. [5]

Melihat dari jumlah bangunan yang ada, maka dalam perencanaan ini penulis merencanakan PHB TR dengan 3 jurusan. Jurusan 1 menyuplai Gedung Dekanat, Mushola dan Sekber. Jurusan 2 menyupali Gedung Jurusan Pendidikan Jasmani Kesehatan dan Rekreasi dan Gedung Serba Guna. Sedangkan Jurusan 3 Menyuplai Gedung PPLM dan PKM. Dari perhitungan KHA rumus yang digunakan adalah

$$
\begin{aligned}
\mathrm{I}_{\text {sekunder }}= & \text { Daya Tersambung } / \sqrt{ } 3 \times 380 \text { Volt } \\
\mathrm{I}_{\text {sekunder }}= & 123564 \mathrm{~W} / \sqrt{ } 3 \times 380 \text { Volt }= \\
& 187,95 \text { Ampere }
\end{aligned}
$$

Berdasarkan hasil didapatkan, maka pemilihan diameter kabel, berdasarkan tabel 3. tentang jenis dan KHA kabel

Tabel 3. Jenis dan KHA Kabel

survey, perencanaan (Gambar \& perhitungan analisa biaya), bangunan, pembelian material dan peralatan sekaligus dengan jasa pemasangannya.

Untuk pelaksanaan pekerjaan pembangunan Gardu Portal Fakultas Keguruan dan Ilmu Pendidikan dan peralatannya meliputi biaya :

1. Material/Peralatan

2. Biaya Pemasangan

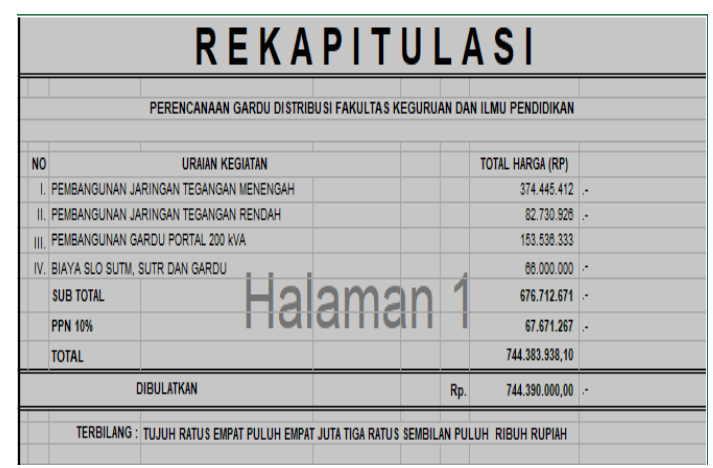




\section{Jurnal IImiah Foristek

\section{KESIMPULAN}

1. Sesuai kebutuhan yang didapatkan, dengan perhitungan analisa perkiraan beban yang digunakan kurang lebih 167,402 kVA sehingga harus menggunakan Gardu Portal dengan kapasitas Transformator yaitu $200 \mathrm{kVA}$

2. Dalam Perencanaan ini, untuk menentukan peralatam yang digunakan harus mengacu kepada standar teknis yang dikeluarkan oleh PT. PLN (Persero) sehingga keamanannya dapat terjamin.

3. Rencana Anggaran Biaya (RAB) yang diperoleh dari perencanaan ini sebesar Rp.744.390.000,00 (tujuh ratus empat puluh empat juta tiga ratus sembilan puluh ribu).

\section{DAFTAR PUSTAKA}

[1]. Anonym,1996,SPLN118-3-I:1996

"Spesifikasi Perangkat Hubung Bagi Tegangan Rendah Gardu Distribusi". Direksi PT. PLN (Persero), Jakarta

[2]. Anonym, 2010, Buku1"Kriteria Disain Enjinering Kontruksi Jaringan Ditribusi Tenaga Listrik".Direksi PT. PLN (Persero), Jakarta.

[3]. Anonym,2010,Buku4"StandarKonstruksi Gardu Distribusi dan Gardu Hubung Tenaga Listrik".Direksi PT. PLN (Persero), Jakarta.

[4]. Hamad S ., Riswanda, 2017 , "Perencanaan Gardu Beton Auditorium Universitas Tadulako, Skripsi, Palu. "

[5]. Panitia Revisi PUIL 2000, Persyaratan Umum Instalasi Listrik 2000 (PUIL 2000) SNI 04-0225-2000, Yayasan PUIL, Jakarta.

[6]. Ridawati, 2013, Perencanaan Gardu Distribusi Khusus Indoor Tegangan Menengah 20kV IAIN Imam Bonjol Padang.
[7]. Suswanto ., D, 2009 , "Sistem Distribusi Tenaga Listrik, Edisi Pertama, untuk Teknik Elektro Universitas Negeri Padang. 